\title{
COVID-19 EXPOSURE \& REPORTING FOR WORK: THE CASE OF CENTRAL FLORIDA'S THEME PARK OPERATIONS EMPLOYEES
}

\author{
Kelly Semrad $^{1}$ and Sean Bliznik ${ }^{2}$ \\ University of Central Florida \\ ${ }^{1}$ Email: Kelly.Semrad@UCF.edu \\ 2Email: Sean.Bliznik@UCF.edu'
}

Cite this article:

Kelly S., Sean B. (2022), COVID-19 Exposure \& Reporting for Work: The Case of Central Florida's Theme Park Operations Employees. Research Journal of Hospitality and Tourism Management 1(1), 1-12. DOI: 10.52589/RJHTM2Q0UWIEA

\section{Manuscript History}

Received: 19 Jan 2022

Accepted: 5 Feb 2022

Published: 22 Feb 2022

Copyright $\odot 2022$ The Author(s). This is an Open Access article distributed under the terms of Creative Commons AttributionNonCommercial-NoDerivatives 4.0 International (CC BY-NC-ND 4.0 ), which permits anyone to share, use, reproduce and redistribute in any medium, provided the original author and source are credited.
KEYWORDS: This exploratory study describes circumstances during the ongoing COVID-19 pandemic where theme park operation employees had to make the difficult decision to stay home to quarantine or go to work sick. Using 35 semi structured interviews with Central Florida theme park operations employees, the research results reveal emerging qualitative themes regarding the employees' ability to chose between staying home to quarantine or going to work sick. The themes include challenging financial situations, fear of layoffs/furloughs, and lack of sick time being major obstacles for theme park employees to stay home from work during the COVID-19 pandemic.

KEYWORDS: COVID-19, Tourism, Theme Park, Florida's. 


\section{INTRODUCTION}

The purpose of this exploratory study is to reveal some of the dangerous hardships that some Central Florida theme park operation employees (frontline workers) have faced during the ongoing COVID-19 pandemic. This qualitative research study reveals unfortunate circumstances for theme park operation employees regarding wages, COVID-19 exposure, and presenteeism while at work. These circumstances play into a nearly "perfect storm" scenario whereupon some theme park employees knew they were exposed to COVID-19 but could not afford to stay home to quarantine, so they reported to work with the potential to spread the disease to others. The hardships referenced within this study pose a threat to not only the employees themselves as well as their families, but also to the greater community regarding the spread of the COVID-19 virus. The major contribution of this study pertains to the need for policies that would protect the health of theme park operations employees as well as the greater community during times of severe public health crisis.

\section{LITERATURE REVIEW}

\section{The impact of COVID-19 on Central Florida's tourism industry}

The onset of COVID-19 had unprecedented negative economic and social impacts on the tourism industry worldwide. In the United States, the state of Florida was hard hit by the dramatic decrease in tourists frequenting some of the world's most popular tourist destinations (e.g., Orlando). Nearly one year into the COVID-19 pandemic, Florida's Department of Economic Opportunity reported that the tourism and hospitality industry had suffered more than any other state sector and had lost billions of dollars and hundreds of thousands of jobs.

During the summer 2020 spike of COVID-19 cases, the State of Florida Employment and Labour Department reported a $10.4 \%$ statewide unemployment rate but reported almost an $18 \%$ unemployment rate in the Central Florida region. The Central Florida region includes major U.S. tourist destinations such as: Orlando, Tampa, Kissimmee, Daytona Beach, Clearwater, St.

Petersburg, Sarasota, Vero Beach, and St. Augustine. The region is home to some of the world's most popular tourist attractions including some world-renowned theme parks. During the pandemic, the higher regional unemployment rate in Central Florida was attributed to the large number of tourism businesses that act as the region's major employers. These businesses were severely impacted by decreased tourist demand during the pandemic resulting in mass job loss.

For example, Orlando, FL, coined the theme park capital of the world, was among the severest hit U.S. tourism destinations (Visit Orlando, 2019). In previous years, Orlando boasted tourism arrival numbers of 75 million visitors, thus ranking the destination as the number one U.S. travel destination (Visit Orlando, 2018). But, as the spread of COVID-19 increased during March 2020, a decrease of \$17.6 million (-57\%) in rooms tax revenue was reported (Orange County Tax Collector Office, 2020). Rooms tax revenue is a measure used within the tourism industry to report upon demand performance. This decrease was a historic low for hotel rooms tax revenue generated in Orlando, FL. 
As the Central Florida region's tourism industry witnessed arrival numbers plummeting in the most popular U.S. tourism destination (Orlando, FL), businesses braced for the possibility that tourist demand would continue to decrease. As this study reveals, simultaneously to businesses expecting slow demand, tourism employees' stress levels began to increase with concern for being furloughed or laid off as they began to witness widespread job loss in the industry.

Unfortunately, the stress of potentially losing a job resulted in some theme park employees reporting for work despite knowing they had been exposed to COVID-19.

\section{Job loss in the Central Florida theme park industry}

The Central Florida theme park industry was severely impacted by a reduction in tourist demand due to the COVID-19 pandemic. Approximately 45,000 theme park employees were furloughed or laid off during the pandemic (WARN, 2021). Central Florida theme park employees witnessed SeaWorld Entertainment furloughing 95\% of its employees. Legoland also laid employees off but did not disclose how many employees were impacted. Disney World laid 32,000 employees off out of a total of 77,000 employees in the state (National Labor Relations Board, 2020). And, Universal Studios Orlando furloughed about 9,000 employees.

\section{The impact of layoffs \& furloughs on theme park employees}

Fear of unemployment resulting from layoffs and furloughs induces stress that is difficult for most people to manage (Tu et al., 2021). Chronic stress impacts employees' cognitive abilities including their ability to concentrate, be creative, generate innovative ideas and solutions, and finish tasks to the best of their ability or even at all (Halbesleben et al., 2013). Unfortunately, the worldwide COVID-19 pandemic induced high levels of stress for many tourism and hospitality employees, particularly those employees in subindustries like the theme park industry where mass layoffs and furloughs were occurring.

Most theme park operation employees are paid hourly and do not have paid leave (Susser, P. \& Ziebarth, N., 2016). Therefore, an absence from work results in a reduction in their pay.

Generally speaking, hourly paid employees in the tourism and hospitality industry are not in the financial situation to be able to afford to take time off of work (Milman, 2003). Literature references situations such as this as producing a condition denoted as "presenteeism" in employees.

Presenteeism is defined as a condition where employees are actually at work but are not actually working (Johns, 2009). In other words, the employee is physically present but they are not productive (Hemp, 2004). This may be because the employee is ill, stressed, depressed, etc.

As more business downsizing horror stories were rumoured and referenced in tourism industry reports, theme park employees' uncertainty regarding the risk of being laid off or furloughed increased (Roy et al., 2021) in Central Florida theme park industry. In the case of a worldwide pandemic (e.g. COVID-19), employee presenteeism may be slightly different than under normal circumstances. For example, in the Central Florida theme 
park industry, employees witnessed mass job loss within a matter of weeks. This observation may have induced unusual stressful situations for some theme park employees who felt it was of paramount importance to report for work to keep their jobs regardless of COVID-19 exposure, feeling ill themselves, or being mentally stressed to the point of decreased productivity.

\section{METHODOLOGY}

\section{The case: The Central Florida region}

The fear of being unemployed in the Central Florida region can be overly concerning for some tourism employees. This is because the region's employees are among the lowest-paid within the U.S. According to the U.S. Bureau of Labor Statistics (2019), the region ranks last in the country for median salaries $(\$ 29,000)$. According to the data, the region also ranks first in the country for jobs that pay less than $\$ 20,000$ a year. The U.S. Federal Poverty Guidelines (2020) indicate that a family of three earning $\$ 21,960$ or less is living in poverty. In the Central Florida region, more than $25 \%$ of the tourism jobs pay less than the U.S. poverty wage.

\section{Research question}

When considering the financial resource constraints of some theme park employees within the Central Florida region, the question begs, during a worldwide pandemic when the fear of being furloughed or laid off is imminent, when employees' financial resources are limited, or if an employee is a part of the families living in poverty - what does the theme park employee do when exposed to COVID-19: or tests positive for COVID-19? Sadly and dangerously, this study reveals that some of the Central Florida frontline theme park employees report for work to earn their wages and to try and keep their job - despite their potential for spreading the disease.

\section{Data collection}

The current study addresses a sensitive research topic for Central Florida theme park employees who report for work when ill or exposed to a contagious disease. The data was collected during a global pandemic. Thus, it was necessary to adopt certain precautionary data collection protocols to reduce the risk of COVID-19 exposure. In order to safely collect the data, the researchers deemed a virtual snowball sampling technique as the most appropriate approach to use for this qualitative study.

Virtual snowballing is a nonprobability sampling technique that requires participants to recruit their acquaintances via their virtual social networks (Dusek et al., 2015). The study's first participant was an individual who was seeking support and information to help solicit funds to pay theme park employees who needed to quarantine after knowingly being exposed to COVID-19. The subsequent participants were recruited by their work acquaintances. In order to ensure anonymity, the respondents were given the researcher's phone number to call and schedule a 30-minute interview. The participants were asked to block their phone numbers prior to calling for their interview. During the interview, the researchers asked six questions: 
Q1: What position did the employee work in at the theme park?

Q2: In general, what COVID-19-related challenges was the theme park-employee facing? Q3: In general, what COVID-19 related challenges did the employee feel or hear their co-workers were facing?

Q4: What COVID-19 policies did the theme park they work at use for customers and for employees?

Q5: Did the theme park employee feel that the COVID-19 policies were being followed and were effective?

Q6: Might you [the employee/interviewee] have been exposed to COVID-19 or tested positive and gone to work? If yes, why did you go to work?

\section{RESULTS}

\section{Data saturation}

Data saturation occurs in qualitative research when the researchers conclude that no additional data are being found in the research process (Guest et al., 2020). Data saturation is a popular means to determine the appropriate sample size for qualitative research (Guest et al., 2020). The researchers of the current study determined that data saturation occurred after completing the $35^{\text {th }}$ theme park employee interview. On average, each interview took about 30 minutes to complete. All 35 interviews were transcribed. Thematic analysis was used to examine the qualitative data to identify common themes and patterns that emerged in the participants' responses to each of the aforementioned six research questions.

\section{Themed responses}

The results from this study produced several general themes for each research question. The themes are assorted according to the six questions that were asked during the interviews.

\section{Q1: What position did the employee work in at the theme park?}

All 35 of the study's respondents worked as frontline theme park employees in Central Florida during the COVID-19 pandemic. Table 1 provides a breakdown for each frontline position that was reported during the interviews.

Table 1. Number of responses for each work position

\begin{tabular}{|l|l|}
\hline \multicolumn{1}{|c|}{ Employee Position } & \\
\hline Attractions & 10 \\
\hline Merchandise & 5 \\
\hline Food and beverage & 4 \\
\hline Custodial & 3 \\
\hline Front Entrance/Ticketing & 6 \\
\hline Grounds maintenance & 5 \\
\hline Entertainment & 2 \\
\hline
\end{tabular}
$\mathrm{n}=35$ 
* All theme park participants were employed within a Central Florida theme park during the COVID-19 pandemic.

Q2: In general, what COVID-19-related challenges was the theme park employee facing? Thematic analysis revealed that there were several themed responses pertaining to this question. The overwhelming majority of respondents answered that the most critical COVID challenges they were struggling with were apart from actual work experiences in the theme park. For example, $80 \%$ of the respondents indicated that their number one challenge related to COVID-19 was missing family and friend interaction.

One respondent indicated the following during the interview,

"In general, The COVID-19 challenges that I am facing pertain to missing my family. I am a family orientated person. I even consider most of my friends as family. I have not been able to see my actual family since the beginning of the pandemic. I work at a theme park so the risk of myself coming in contact with COVID and giving it to my family members is too high. I feel isolated from my family and friends and very lonely."

Similarly, another respondent indicated their miss for family interaction in the following interview statement,

"This is the longest I have been without seeing my family. In my culture, family is everything. If I gave the disease to anyone in my family I don't know what will happen to that person. I stay away from my family voluntarily so that I don't accidentally spread the disease. I know that I am coming in contact with the disease because of where I work [theme park]. I

accept this risk for myself but not for my family. It is critical that I stay home except for going to work. I constantly stay in quarantine except for going to work. I miss my family like no other. It has been lonely but I think it is necessary to stay away from my family - for their protection."

The second most common answer for this question pertained to childcare and homeschooling due to the pandemic. A respondent indicated the following,

"I am so concerned about my kids and their school. I cannot teach them their school lessons. I am not a teacher but I am keeping my kids home and away from school and their friends because one of them is at high risk if they get the disease. They are not going to school because of COVID. I have to leave them by themselves to do their schoolwork while I go to work. I am so stressed out because I am worried that I will catch the virus and spread it to my kids. I feel like I am choosing between my kids' health and paying my bills. I am currently looking for another job [not in a theme park] that I feel is less risky when it comes to virus exposure.

Another respondent said the following pertaining to homeschooling,

"I am really worried about my kids at school but I have to send them. I cannot teach them their school lessons. I did not graduate from high school myself. I am a single mom. It is hard right now. I have to send them [my kids] to school because I can't 
stay home too. I have to go to work and they are too young to be alone. It is really hard and stressful right now."

Regarding daycare, a respondent stated the following,

"Daycare is super expensive. I send my kids to an affordable childcare program. Right now, the classrooms are closed on and off because of COVID exposure. If the classroom closes, I can't afford to send them to another daycare. It means that I have to take off of work or find someone to watch my children for free. I am worried if I take off of work too much that I will red flag myself to lose my job. At the same time, I won't leave my kids alone and I don't always have someone who could watch them that I trust. It's super stressful. I think the theme park should address this issue and have on sight child care. There are many employees in the same situation."

Another common COVID challenge that Central Florida theme park employees were encountering was transportation to work. Approximately, $63 \%$ of the respondents indicated that they depend upon public transport to get to work. However, the pandemic induced some unexpected impacts on the theme park employees' ability to get to work. One interviewee revealed the following COVID-19 related challenge.

"I have been taking the same bus route for two years to get to work. My bus time commute is already almost two hours because the public transportation system here is not good. There used to be, I don't know, maybe 50 to 65 people on a bus. Now, I am being passed by at the bus stop by two sometimes three buses because capacity is limited to 20 people to prevent crowds. I am going to lose my job if I continue to be late but I can't get to work with this type of transportation issue. This ain't my fault. I can't afford to lose my job. I can't leave my house any earlier. I have kids that I have to get off to school. They can't stay home from school like other kids. The home lessons require the internet. We don't have a home internet connection and using a hot spot takes too much data."

Another interviewee revealed the following information,

"I am just worried about getting to work today and on a daily basis. My commute time is taking almost an extra hour to get to work. I am sure that I will either lose my job for being chronically late or lose my job because I will catch this virus and won't be able to go to work. I am around [theme park] people all day. Who knows if they are positive or not. And, then, I am on the bus twice a day breathing the same air as everyone else on the bus. I'd say the chances of me getting the virus are high. This is stressful but not as stressful as trying to get to work right now."

The fourth most common answer pertained to stress in general and the employees' ability to cope with that stress. Approximately, $60 \%$ of the employees interviewed indicated stress was a COVID-19 challenge for them. One interviewee shared the following,

"I am not lying. This is the most stressed I have been in my life. I am worried about getting the disease. I am worried about giving the disease to my family. I work in the worst spot for catching it [COVID-19] - a theme park. I am stressed about losing my job. Every day I go to work and the shift people are changed. I am thinking because they are either sick or let go or furloughed, which is just the polite way of saying 
you've been let go. I am at work but mentally I am a zombie. I don't want to be there during this time. I can't afford to take time off of work. People think it's funny when I say it but I think I need some medication ...for real to deal with this stress."

Another employee revealed the following information pertaining to stress as a COVID-19 challenge,

"Stress comes in a lot of different forms these days. Emotional. Physical. Mental. I am doing my best to be safe and not get the disease. I look at the people coming to the park on vacation or for a day off to have fun and I get angry. I think... I have to work. I have to be here. I have to earn money to pay my rent and eat. What is your excuse for being out and risking spreading the disease to other people? I feel constantly stressed. I am mostly trying to observe anyone who looks sick at work (coworker or customer) so I can avoid them. I zone out a lot lately and stare at the clock until it's time for me to go. I need my job but I need to be healthy more. This creates constant stress for me. I am not sure if I should quit. I don't know if other jobs are available and I can't afford to not work for even a day. Mentally, I checked out while I am at work. The less I think the better for me right now."

One interviewee stated the following about stress levels in general as a COVID-19 challenge,

"I know that this is hard times for everyone. The whole world. But some people are better off than others. When I look around and look at the people, most of us need this job. None of us can afford to get sick. None of us knows if we can get a job anywhere else because everything is shutting down. Do you know what kind of stress that is? It is actually more fear than stress.

Fear is contagious. The people I am working with all talk, 'who is next?' Which park is going to lay off next? I think if supervisors would just acknowledge that this is a scary stressful time it might do a lot to ease people's fears. Where I work, they seem to make it be rosy [meaning] that we will all keep our jobs and then BAM! A bunch of people are let go. The supervisors don't understand that people are afraid to lose their jobs and how they will pay bills but still expect us to deliver great customer service. Umm ... that doesn't add up."

Sprinkled in throughout the interviews, about $58 \%$ of the respondents revealed that the stress from the ongoing pandemic circumstances had stressed them to a point that their work productivity was severely impacted. Respondents used the phrasing that they "zone out at work, are a zombie at work, they don't want to be at work during these times, they are [mentally] checked out while at work." Answers like these revealed a form of presenteeism emerging in some theme park frontline employees.

\section{Q3: In general, what COVID-19 related challenges did the employee feel or hear their} co-workers were facing?

The interviewed employees did not express alternative challenges for their coworkers than what they stated were their COVID-19 challenges. The thematic analysis revealed that the majority of the participants expressed the following two challenges they heard coworkers discussing: 
Concern 1: Being exposed to the disease, becoming ill, and spreading the disease to their family and friends ( $72 \%$ of respondents).

Concern 2: Staying employed, being laid off, being furloughed ( $84 \%$ of respondents).

Q4: What COVID-19 policies did the theme park they work at use for attendees and for employees?

Most of the participants indicated that the COVID-19 policies that had been adopted for attendees were recommended by the Centre for Disease Control (CDC). These policies included closing the park for a limited time, increasing sanitation protocols/cleaning, hand sanitiser stations, social distancing, wearing of face masks, and once the parks opened, decreased occupancy. Attendees who entered the park were also required to have temperature checks at the entrance. Some of the theme parks had additional COVID protocols such as requiring attendees to make reservations in advance to arriving at the park as well as completing a COVID-19 check-in test that asked attendees about recent contact with the virus or virus symptoms.

In terms of the COVID-19 policies that were required of employees. Most of the COVID19 protocols and procedures for theme park employees were also recommended by the CDC, which served as a guide for public health and safety for theme park operations. The employees indicated that they were required to use social distancing, face coverings, wash hands frequently, undergo temperature checks prior to entering the park for work, increased sanitation of work stations, increased washing of hands, and were required to complete COVID-19 self-check-in tests.

The self-check-in tests asked the employee if they had experienced any COVID-19 related symptoms, if they had been tested for COVID-19, or if they had been exposed to COVID19. Additional theme park precautionary operations included: one employee admitted to a restroom at a time, all employees requiring microphones to have their own microphones, a limited amount of employees allowed on a park bus/transit, a limited amount of employees permitted in break rooms, entertainment events/shows were suspended, and congregation in employee common areas was prohibited.

Q5: Did the theme park employee feel that the policies were being followed and were effective?

The employees who were interviewed indicated that they felt as though the park attendees followed the COVID-19 policies and procedures to the best of their ability. The employees revealed that they weren't sure if the policies were effective but it did not seem there were any cases traced back to the theme parks. The interviewed employees indicated that the park was staffed with employees to enforce the policies and procedures when they saw a violation. All in all, the employees felt there was little resistance from park attendees and that for the most part, they witnessed people trying to be careful and abide by the COVID-19 rules. The employees felt the theme park attendees followed the COVID-19 policies to the best of their abilities.

When the interviewee respondents were asked if the theme park employees followed the COVID-19 protocols and procedures, the majority of the respondents $(92 \%)$ indicated that they tried to follow the COVID-19 rules to the best of their ability. However, many of the 
employees indicated that there were some instances (e.g. face coverings) where they could not always follow the required protocol because they would lose their breath or become too uncomfortable. For example, one employee stated the following regarding wearing a face mask while at work,

"I do my best to follow all of the COVID-19 rules for employees. I do pretty good. I keep my distance from other people, I use the hand sanitation stations - a lot, and I try to keep my facemask on. The only one I really struggle with is the facemask. We have had some days where mask-wearing is very uncomfortable because of heat. I lose my breath. Ifeel like I cannot catch my breath. So, I put my nose out of my mask. I see a lot of my co-workers do the same thing."

Q6: Might you [the employee/interviewee] have been exposed to COVID-19 or tested positive and gone to work?

An insightful result pertains to the COVID-19 self-check-in tests. One hundred percent $(100 \%)$ of the employees indicated that on at least one occasion they knew they either had been exposed to COVID-19 directly or indirectly. Direct exposure was defined as a person they lived with or worked with in close proximity who had tested positive for COVID- 19 . Indirect exposure was defined as the employee having come in contact with COVID-19 through trace contacts.

The employees indicated that because they were frequently coming in contact with the disease (either direct or indirect), they could not always answer some of the questions on the COVID-19 self-check-in test in an honest fashion. This is because they would be sent home if they truthfully answered the question that they had come in contact with the disease. The employees indicated that they knew if they were exposed to COVID-19, they were required to "call out" of work due to COVID-19 related exposure. Theme park employees were instructed that if they were exposed to COVID-19, they should quarantine per the CDC recommended length of time or get a COVID-19 test prior to returning to work. However, all of the employees interviewed indicated that this protocol was not feasible given the high rate of exposure. Therefore, the employees seemingly depended upon the temperature checks at the park entrances to determine if they were COVID-19 sick.

For example, one employee indicated the following during the interview,

"I follow the COVID-19 rules where ever I go. No matter where I go. I follow if I am at work or in the grocery store. I don't want to get sick and I don't want to make others sick. But, on the COVID-19 self-check-in test [there is a question] that asks if I was directly or indirectly exposed to the disease. My truthful answer would have to be, 'Yes, all the time,' but instead, I check the NO box. I can't afford to not come to work. They take temperature checks at the entry points. If I am sick, my temperature will report it and then I can go home."

Another employee indicated the following,

"I tested positive for COVID-19 4 days ago. I don't have any symptoms. I check no on all the COVID test questions. I don't feel sick. A little tired. I try to stay further away from people than usual but I gotta work. Bills don't pay themselves. I don't think I am spreading the disease if I stay as far away from people as possible. Also, 


\section{the theme parks are outside so I doubt the virus can really spread-I hope."}

The most prevalent theme for why people went to work when they knew they had been directly or indirectly exposed to the virus included the following. Theme park employees could not afford to miss their scheduled shifts and stay home to quarantine. They did not have paid sick leave. These employees indicated they went to work and did not report their exposure to COVID-19 during the screening tests required before each shift. Lastly, 14 of the respondents indicated that at one point during the pandemic, they had tested positive for COVID-19 but were asymptomatic. According to the respondents, they misreported the results of a positive COVID- 19 test and reported for work while trying to be extra careful to social distance because they could not afford quarantine and their symptoms were relatively mild.

\section{CONCLUSION AND DISCUSSION}

The major results from this study reveal that Central Florida frontline theme park employees were highly stressed during the COVID-19 pandemic. Many of the employees expressed experiencing an unusually high level of stress due to fear of virus exposure, feeling isolated from their family and friends, and being concerned that they would lose their theme park job. Many of the employees tried to stay in self-quarantine when not at work because of increased fear that they would spread the disease to friends and family members. The employees indicated that they were highly concerned about losing their theme park jobs due to mass job layoffs in the Central Florida tourism region.

The study's results indicate that the employees' fear of job loss compounded from pandemic stress seemingly presented a condition referred to as presenteeism whereupon the employees were present at work but their work productivity or mental awareness of being at work was relatively lower than usual. Additionally, the theme park employees all revealed that they felt both park attendees and employees tried to comply with the COVID-19 policies and procedures to decrease the spread of the virus. However, $100 \%$ of the interview respondents indicated that there were numerous times that they were either directly or indirectly exposed to COVID-19 but reported to work because they could not afford to stay home or were afraid they might be in the next round of layoffs if they did not report for work. Sadly, some employees indicated that they went to work if they were COVID-19 positive but were asymptomatic or had mild symptoms - if they could pass the temperature checks at the entrance gates.

A major implication of this study demonstrates the need to have a reserve for public health and safety funds and policy whereupon frontline hourly paid employees in the tourism industry (e.g. theme parks) have the ability to request paid leave to properly quarantine when they can demonstrate they have been directly or indirectly exposed to a contagious disease. Customarily, these employees do not have financial savings that would permit them from missing or calling out of work when exposed to a contagious disease. In the case of COVID19 self-check-in tests, some of the Central Florida theme park employees could not afford to be honest with their test answers and risked spreading the disease to others in the community 


\section{REFERENCES}

Dusek, G., Yurova, Y., \& Ruppel, C. (2015). Using social media and targeted snowball sampling to survey a hard-to-reach population: A case study. International Journal of Doctoral Studies, 10(1), 279-299.

Florida Department of Economic Opportunity. (2020). Florida Jobs. Retrieved from https://floridajobs.org/workforce-statistics/workforce-statistics-datareleases/latest- statistics.

Florida example. International Journal of Hospitality Management, 22(1), 17-35.

Guest, G., Namey, E., \& Chen, M. (2020). A simple method to assess and report thematic saturation in qualitative research. PLOS ONE, https://doi.org/10.1371/journal.pone.0232076.

Halbesleben, Jonathon R. B.,Wheeler, Anthony R., Paustian-Underdahl, \& Samantha C. (2013). The impact of furloughs on emotional exhaustion, self-rated performance, and recovery experiences. Journal of Applied Psychology, 98(3), 492-503.

Hemp, Paul. "Presenteeism: At Work-But Out of It." Harvard Business Review. October 2004. Johns, Gary. (2010). Presenteeism in the workplace: A review and research agenda. Journal of

National Labor Relations Board. (2020). WARN. Retrieved from https://www.nlrb.gov/. Milman, Ady. (2014). Hourly employee retention in small and medium attractions: The Central

Office of the Assistant Secretary for Planning \& Evaluation. (2020). HHS Poverty Guidelines.

Organizational Behavior, 31(4), 519-542.

Retrieved from https://aspe.hhs.gov/poverty-guidelines.

Roy, Satyaki, Dutta, Ronojoy, \& Ghosh, Preetam. (2021). Recreational and philanthropic sectors are the worst-hit US industries in the COVID-19 aftermath. Social Sciences and Humanities Open, 3(1), 1-5.

State of Florida Employment \& Labor Department. (2020). Employment Report. Retrieved from https://www.stateofflorida.com/employment/.

Susser, Philip and Ziebarth, \& Nicolas, R. (2006). Profiling the U.S. Sick Leave Landscape: Presenteeism among Females. Health Services Research, 51(6), 2305-2317.

Tu, Yidong, Li, Diwan, \& Wang, Hai-Jiang. (2021). COVID-19-induced layoff, survivors' CPVID-19-related stress and performance in the hospitality industry: The moderating role of social support. International Journal of Hospitality Management, 95(1) 1-8.

U.S. Bureau of Labor Statistics. (2019). Beyond the Numbers. Retrieved from https://www.bls.gov/.

U.S. Travel Destination. Retrieved from https://www.globenewswire.com/newsrelease/2019/05/10/1821626/0/en/Orlando-Announces-Record-75-MillionVisitors- Solidifies-Ranking-as-No-1-U-S-Travel-Destination.html.

Visit Orlando. (2019). Orlando Announces Record 75 Million Visitors, Solidifies Ranking as No. 